\title{
Den Münzen der römischen Republik verpflichtet - Der Numismatiker Max von Bahrfeldt (1856-1936) ${ }^{1}$
}

\author{
Matthias Willing
}

\section{Einleitung}

Auf dem Gebiet der klassischen Altertumswissenschaften ist der Name Max von Bahrfeldt heute kaum noch ein Begriff, ${ }^{2}$ obwohl er mit Theodor Mommsen bekannt war und ein reichhaltiges Euvre hinterlassen hat. Zur Erklärung für die ausbleibende Anerkennung muss insbesondere auf seine Sonderstellung im Fach verwiesen werden. Als der Numismatiker sich dem Studium der Münzen widmete, war er von Beruf preußischer Offizier, sodass er zunächst nicht an einer Universität unterrichtete, sondern seinem Forscherdrang privat durch die Veröffentlichung von einschlägigen Untersuchungen nachkam. Erst durch die Ernennung zum Honorarprofessor für Münzkunde 1921 konnte er akademisch reüssieren und eine Laufbahn als Hochschullehrer starten, die etwa 14 Jahre mit nur einer Station an der Universität Halle (Saale) umfasste. ${ }^{3}$ Dass er als Vertreter einer „Hilfswissenschaft“ eher eine randständige Figur blieb, ist daran abzulesen, dass er in den führenden Periodika „Gnomon“, „Klio“ oder „Historische Zeitschrift (HZ)“ nicht veröffentlichte und dort kein Nachruf sein Andenken ehrte. Außerdem verdient erwähnt zu werden, dass der Kommandeur im Ersten Weltkrieg eine fragwürdige Rolle beim deutschen Vormarsch im Westen gespielt hatte, weswegen er 1925 in Abwesenheit von einem belgischen Gericht zum Tode verurteilt wurde.

Aus diesem ungewöhnlichen Lebenslauf ergeben sich Disposition und Intention des nachfolgenden Beitrags, wobei der Fokus primär auf der historischen Forschung und weniger auf der militärischen Laufbahn liegt. Zunächst soll als Orientierung ein chronologisch angelegter Überblick über den Werdegang Max von Bahrfeldts gegeben werden (2.), ehe die niedersächsische Münzkunde (3.) und die antike Numismatik (4.) in den Blick gerückt werden. Ein gesonderter Abschnitt ist den Aktivitäten des Befehlshabers in Belgien 1914 sowie den daraus resultierenden politischen Verwicklungen in Weimarer Republik und Nationalsozialismus gewidmet (5.). Ein weiteres Kapitel beleuchtet das Handeln an der Universität Halle-Wittenberg (6.), ehe in einer Zusammenfassung (7.) versucht wird, eine Gesamtbilanz seiner facettenreichen Persönlichkeit zu ziehen. Der Beitrag soll helfen, die Frage zu beantworten, inwieweit der Numismatiker zeittypische Züge für seine Generation und Profession verkörperte. Von der Erstellung eines Schriftenverzeichnisses wurde abgesehen, da davon auszugehen ist, dass der Münzexperte über 1.000 Publikationen der vielfältigsten Art und Qualität hinterließ, die auf nicht wenige internationale Zeitschriften verstreut sind. ${ }^{4}$ Dennoch sollen in einem Quellen- und Literaturverzeichnis (8.) die wichtigsten Veröffentlichungen von

\footnotetext{
${ }^{1}$ Vgl. Universitätsarchiv Halle-Wittenberg (UAHW), 4080; Gothaisches Genealogisches Taschenbuch der Adligen Häuser (1941), S. 18-19; Kürschners Deutscher Gelehrten-Kalender (1931), S. 82-83; Gaettens (1936); Pink (1936); Woermann (1937); Jesse (1953); Catalogus Professorum Halensis, Bahrfeldt (Zugriff: 11. Januar 2021).

${ }^{2}$ Christ (2006); Geschichte der Altertumswissenschaften (2012).

${ }^{3}$ Schulz-Falkenthal (1961); Prokoph (1985); 100 Jahre Archäologisches Museum in Halle 1891-1991 (1991); Eberle (2002); Meißner (2002).

${ }^{4}$ Gaettens (1936), S. 414.
} 
und über Max von Bahrfeldt aufgelistet werden, um die Nachprüfbarkeit des hier gezeichneten Bildes zu ermöglichen.

\section{Das Leben des geadelten Offiziers}

Max Ferdinand Bahrfeldt wurde am 6. Februar 1856 in der kleinen Siedlung Wilmine im Kreis Templin in der Uckermark als zweiter Sohn eines Rittergutsbesitzers geboren. ${ }^{5}$ Er besaß das evangelische Bekenntnis. Über seine Kindheit und Jugend in der ländlich geprägten Provinz, etwa 60 km nördlich von Berlin gelegen, ist kaum etwas bekannt. Sein älterer Bruder Emil (1850-1929), studierter Landwirt, entwickelte sich zu einem erfolgreichen Bankier und wurde 1888 in Tübingen zum Dr. phil. promoviert. Als angesehener Numismatiker gab er die Zeitschrift „Berliner Münzblätter“ heraus. Beide Brüder standen sich fachlich sehr nahe. ${ }^{6}$ Für Max, der gleichfalls für die Münzkunde interessiert wurde, die eine standesgemäße Beschäftigung für Angehörige der Oberschicht darstellte, war die Offizierslaufbahn bestimmt.

Die erste Station auf dem Weg zum Berufssoldaten bildete die 1838 ins Leben gerufene Kadettenanstalt Wahlstatt in Niederschlesien. ${ }^{7}$ An diesem renommierten Gymnasium trugen die Zöglinge eine Uniform aus dunkelblauem Stoff mit roten Aufschlägen und „goldenen“ Knöpfen sowie eine Schirmmütze mit Kokarde. Der streng reglementierte Tagesablauf umfasste neben dem Unterricht in Latein, Französisch, Englisch, Mathematik, Geografie, Musik und „vaterländischer“ Geschichte auch körperliche Ertüchtigung wie Turnen, Schwimmen oder Exerzieren. Prominentester Eleve von Wahlstatt war der spätere „Held von Tannenberg“ und Reichspräsident, Paul von Hindenburg (1847-1934). ${ }^{8}$ Im Anschluss an das provinzielle Internat wechselte Max an die Kadettenanstalt in Berlin, die damals als Synonym für eine Eliteeinrichtung galt. Dort legte er 1873 einen höheren Schulabschluss, vergleichbar mit dem Abitur, ab. 1878 heiratete er Elisabeth Mary Charlotte Samwer (1859-1954), die Ella genannt wurde. Aus dieser Verbindung gingen die Kinder Max Karl Rudolf(1880-1964), Victor Emil Heinrich (1883-1916), Erna Sophie Klara Helene Marie (1888-?) und Ellen Magdalene Emilie Anna (1890-?) hervor. ${ }^{9}$ Eine Reise anlässlich der Goldenen Hochzeit führte das Ehepaar 1928 auf die hispanische Halbinsel. ${ }^{10}$ Erst nach 58 gemeinsamen Jahren beendete der Tod des Mannes den Ehebund. ${ }^{11}$

Der junge Familienvater wurde von 1882-1885 als „Premier-Lieutenant“ an die Kriegsakademie Berlin abkommandiert, ${ }^{12}$ die Kaderschmiede für preußische Offiziere. Dort wurden Taktik, Heerwesen, Kriegsgeschichte, das Leben berühmter Persönlichkeiten (z. B. Friedrichs des Großen), Waffenlehre, Befestigungslehre, Feldkunde, Krokieren, Kartenlehre, Kriegsspiele, Verpflegung der Truppe, Geschichte mit Schwerpunkt Preußens, Erdkunde, Mathematik sowie moderne Fremdsprachen gelehrt. Auch das klassische Altertum fand im Unterricht angemessene Berücksichtigung. ${ }^{13}$ In scharfem Wettbewerb mit ihren Kameraden hatten die jungen Offiziere eine anspruchsvolle wissenschaftliche Ausbildung zu durchlaufen und den Nachweis ihrer Befähigung zur

\footnotetext{
${ }^{5}$ In der biografischen Literatur wird der Vater auch als „Gutspächter“ bezeichnet.

${ }^{6}$ Bahrfeldt, Emil (1901-1929); MvB (1932b); MvB (1930c).

${ }^{7}$ Heute: Legnickie Pole in Polen.

${ }^{8}$ Zedlitz und Neukirch (1989), S. 60-62.

${ }^{9}$ Gothaisches Genealogisches Taschenbuch der Adligen Häuser (1941), S. 18 f.

${ }^{10} \mathrm{MvB}(1933 / 34)$, S. 744.

${ }^{11}$ Vgl. MvB (1927-1930), Bd 2, S. II; MvB (1927-1930), Bd. 3, S. VI.

${ }^{12}$ MvB (1883), S. 5; Eberle (2002), S. 364.

${ }^{13}$ Krafft (1907), S. 442-446.
} 
Truppenführung in einer Vielzahl von Prüfungen nachzuweisen. Beste Gesundheit und geordnete Geldverhältnisse waren unabdingbare Voraussetzung für das erfolgreiche Absolvieren der Akademie.

Neben der Beherrschung von Englisch, Französisch, Italienisch und Russisch, ${ }^{14}$ verfügte der Numismatiker nach eigenen Angaben über gewisse Spanisch-Kenntnisse. ${ }^{15}$ Hinzu traten akademische und militärische Schulungen, die ihn für eine Karriere in der preußischen Armee prädestinierten. Rasch stieg er seit 1873 vom jungen Leutnant auf der beruflichen Leiter nach oben, wurde in Bremen, Stade, Harburg, Rastatt (Baden), Halle an der Saale, Breslau (heute: Wrocław, Polen), Gumbinnen (heute: Gussev, Russland) und Rastenburg (heute: Kętrzyn, Polen) stationiert. ${ }^{16} 1904$ erfolgte die Beförderung zum Oberst, 1908 zum Generalmajor und 1911 zum Generalleutnant. In diesem hohen Dienstgrad amtierte er als Kommandeur der 37. Division in Allenstein (Ostpreußen), dem heutigen Olsztyn in Polen. Am 16. Juni 1913 wurde er anlässlich des 25-jährigen Thronjubiläums von Kaiser Wilhelm II. in den erblichen Adelsstand erhoben und nach 44 Dienstjahren in den Ruhestand entlassen. Die „Exzellenz“ durfte sich fortan als ,von“ Bahrfeldt anreden lassen. Als zivilen Wohnsitz wählte er Hildesheim, doch sorgte die besondere Situation nach der „Juli-Krise“ 1914 dafür, dass der Pensionär reaktiviert wurde.

Am 2. August 1914 übernahm er das Kommando der 19. Reservedivision des 10. Reserve-Korps Hannover, so dass an die Stelle von „Krieg spielen“ das blutige „Krieg führen“ trat. Nachdem die belgische Grenze überschritten worden war, gelangten die vorrückenden Soldaten nach Charleroi, wo sie am 22. und 23. August auf energischen Widerstand stießen. Die Befehle, die von Bahrfeldt den deutschen Einheiten gab, führten rund zehn Jahre später zu seiner Verurteilung als Kriegsverbrecher von einem belgischen Gericht in Mons (siehe Abschnitt 5). Zum General der Infanterie befördert, musste sich der inzwischen 60-Jährige aus gesundheitlichen Gründen von der Front zurückziehen und hatte am 1. Juni 1916 den Tod seines Sohnes Victor in der Seeschlacht am Skagerrak zu beklagen. ${ }^{17}$ Für militärische Verdienste wurden ihm insgesamt 14 Orden und Medaillen verliehen. ${ }^{18}$ Nach dem endgültigen Abschied von der Armee nahm er die numismatischen Tätigkeiten in seiner ,zweiten“ Heimatstadt Hildesheim wieder auf.

Während seiner aktiven Zeit als Berufsoffizier hatte sich der Brandenburger intensiv mit dem Studium von Münzen als Quellen der historischen Forschung beschäftigt und sich in Fachkreisen einen guten Ruf erworben. Die erste Veröffentlichung zu dem Themenkomplex wird in das Jahr 1874 datiert, als er gerade einmal 18 Jahre alt war. ${ }^{19}$ Bereits im Folgejahr wurde er neben H. Walte Mitherausgeber des „Numismatisch-Sphragistischen Anzeigers“, einer seit 1870 erscheinenden „Zeitung für Münz-, Siegel- und Wappenkunde“. ${ }^{20} \mathrm{Zu}$ diesem,,anspruchslosen Blättchen“ gab er als Beilage das „Literatur-Blatt“ heraus, aus dem 1880 das „Numismatische Literatur-Blatt“ hervorging. ${ }^{21}$ In der preisgünstigen Postille wurde über in- und ausländische numismatische Zeitschriften, Neuerscheinungen, Medaillen, Wappen, Metrologie und Geldlehre, verstorbene Mitglieder, Händlerkataloge, Tauschangebote sowie Versteigerungen

\footnotetext{
${ }^{14}$ Möglicherweise war der Offizier an der Kriegsakademie Berlin zeitweilig als Sprachenlehrer tätig; vgl. Gaettens (1936), S. 410.

${ }^{15} \mathrm{MvB}(1933 / 34)$, S. 744.

${ }^{16}$ Gaettens (1936), S. 410.

${ }^{17}$ Gothaisches Genealogisches Taschenbuch der Adligen Häuser (1941), S. 19.

${ }^{18}$ Personalbogen Max von Bahrfeldt (1924). In: UAHW 4080.

${ }^{19}$ Gaettens (1936), S. 410.

${ }^{20} \mathrm{Vgl}$. MvB (1876a).

${ }^{21} \mathrm{MvB}$ (1923), S. VII.
} 
informiert. Sie deckte das gesamte zeitliche Spektrum des Geldes von antiken Prägungen bis zu Gedenkplaketten der Gegenwart ab, wobei die ,grösstmögliche Vollständigkeit angestrebt wurde. ${ }^{\text {“22 }}$ Um dieses Organ kreisten unentwegt die Gedanken des unermüdlichen Autors, Herausgebers, Besitzers und Verlegers, sodass er für 52 Jahrgänge verantwortlich zeichnete. ${ }^{23}$ Als scharfzügiger Zensor kommentierte er nicht selten bissig, z. B. schrieb er über das Werk eines Kollegen: „Steckt voller Fehler, veralteter Ansichten und irriger Auffassungen. “24 Gelegentlich bot es auch bekannten Altertumswissenschaftlern, wie dem Ungarn Andreas Alföldi (1895-1981), ein Forum zur Publikation. ${ }^{25}$

Mit dem „Numismatischen Literatur-Blatt“" war nach dem Ersten Weltkrieg auch eine neue Lebensphase des Zivilisten Max von Bahrfeldt verbunden. Um nicht infolge der zunehmenden Geldentwertung privat Mittel zuschießen zu müssen, unterbreitete er dem Chef des Hallenser Verlages A. Riechmann \& Co., Richard Gaettens (1886-1965), das Angebot, das Münzjournal herauszugeben, was auf Zustimmung stieß. Aus der persönlichen Bekanntschaft mit Gaettens entwickelten sich weitere fachliche Initiativen. Der Pensionär arbeitete seit Beginn der 1920er Jahre intensiv in den „Blättern für Münzfreunde“ (Dresden) mit, die gleichfalls im Riechmann-Verlag erschienen. Ferner konnte die Serie „Münzstudien“, deren altertumswissenschaftliche Schriftleitung von Bahrfeldt seit 1923 übernommen hatte, im selben Haus ediert werden. Gaettens hatte zudem in der Münzhandlung 1918 eine Abteilung für Antike Numismatik eingerichtet, für die der wenig bekannte Althistoriker der Universität HalleWittenberg, Oscar Leuze (1874-1934), verantwortlich zeichnete. ${ }^{26}$ Als Leuze 1921 einen Ruf nach Königsberg (heute: Kaliningrad, Russland) erhielt und annahm, wurde der 65-Jährige an der Alma Mater Halensis zum Honorarprofessor ernannt und bot Lehrveranstaltungen in der ganzen Breite der Münzkunde an. ${ }^{27}$ Während der 1920er und frühen 1930er Jahre erreichte er publizistisch den Höhepunkt seiner Karriere und legte eine ganze Reihe einschlägiger Buchtitel sowie längerer Aufsätze vor.

Von Bahrfeldt amtierte als Vorsitzender des Historischen Vereins für Niedersachsen in Hannover ${ }^{28}$ und war später in der Numismatischen Gesellschaft in Halle (Saale) aktiv. ${ }^{29}$ Bei den Münzforschern in Dresden wurde er Ehrenmitglied. ${ }^{30}$ Als Anerkennung für seine Leistungen wurden ihm Zugehörigkeiten zu mehreren Gesellschaften des In- und Auslandes verliehen, darunter 1912 die Medaille der Royal Numismatic Society in London. Hinzu kamen entsprechende Auszeichnungen in Berlin, Wien, Moskau, Budapest, Bukarest, Genf und Amsterdam. ${ }^{31}$ Am 19. Mai 1926 würdigte ihn die „Svenska Numismatiska Föreningen“ in Stockholm mit einer weiteren Ehrenmitgliedschaft. ${ }^{32}$ Um die Vielzahl der bedeutenden Kabinette inspizieren zu können, unternahm er regelmäßig Studienfahrten ins europäische Ausland. ${ }^{33}$ Nach dem Ersten Weltkrieg zählte er von ihm besuchte Sammlungen römischer Münzen in folgenden Orten auf: Arolsen, Basel, Cassel, Colmar i. E., Donaueschingen, Frankfurt a. M., Freiburg i. Br.,

\footnotetext{
${ }^{22} \operatorname{MvB}(1880)$, S. 1.

${ }^{23}$ Vgl. MvB (1933), S. 2661.

${ }^{24}$ MvB (1909a), S. 1413.

${ }^{25}$ Alföldi (1930); Alföldi (1931); Christ (1990); Kolb (2012).

${ }^{26}$ Theiler (1934).

${ }^{27}$ Personal- und Vorlesungsverzeichnis der Universität Halle, Halle 1922-1935; vgl. Abschnitt 6.

${ }^{28}$ Berger (1989), S. 7.

${ }^{29}$ Vgl. Gelehrte Gesellschaften und Vereine (1924), S. 15 f.; 32; 48; 128.

${ }^{30}$ Gelehrte Gesellschaften und Vereine (1936), S. 476.

${ }^{31}$ Personalbogen Max von Bahrfeldt (1924). In: UAHW 4080.

32 Personalnachrichten (1926).

${ }^{33}$ MvB (1933/34), S. 742 f.
} 
Pforzheim, Stuttgart, Winterthur, Zürich, Paris, London, Oxford, Cambridge, Glasgow, Haag, Kopenhagen, Dresden, Gotha, Rom (Vatikan, Kapitol, Museo Nazionale Romano), Florenz, Mailand, Venedig, München und Wien. ${ }^{34}$

Im Herbst 1922 waren Österreich, Ungarn, die Tschechoslowakei und Jugoslawien das Ziel der Erkundungen, ${ }^{35}$ an die sich Fahrten nach Italien, Sizilien, Spanien und Portugal anschlossen. Diese Auslandsaufenthalte wurden sorgfältig vorbereitet und dienten der Gewinnung von numismatischem Material. Ausgestattet mit Stanniol, Plastilin und Bürste fertigte er von interessanten Geldstücken Gipsabdrücke an, um sie später auswerten zu können. Anerkennung genoss der Fachmann für Münzkunde bei Theodor Mommsen (1817-1903), mit dem er bekannt war. Als der ihn kurz vor seinem Tod zur Mitarbeit an einer Neuauflage des ersten Bandes des Corpus Inscriptionum Latinarum (CIL) einlud, dauerte es 27 Jahre, bis der Münzkatalog für die zweite Auflage unter der Redaktion von Hermann Dessau (1856-1931) fertiggestellt wurde. ${ }^{36}$ Regelmäßig referierte der preußische Offizier in seinem Journal über Veröffentlichungen Mommsens, sofern sie geldgeschichtliche Bezüge aufwiesen. Auch bei Treffen von Gleichgesinnten verstand er es, sich in Szene zu setzen. Auf dem 3. Münzforschertag 1924 in Frankfurt am Main trug er zu den niedersächsischen Probationstagen vor. ${ }^{37}$ Auf dem 4. Deutschen Münzforschertag in Halle 1925 zeigte er sein Organisationstalent, beschäftigte sich mit den Schaumünzen der Universität Halle und hielt zwei Referate. ${ }^{38}$ Auf dem 5. Deutschen Münzforschertag in Wien, der vom 12.-14. September 1928 stattfand, berichtete er über die Erfahrungen während seiner jüngsten Spanienreise. ${ }^{39}$

1917/18 wurde von Bahrfeldt Mitglied der „Deutschen Vaterlandspartei“ (DVLP), die in der hoffnungslosen militärischen Lage am Ende des Ersten Weltkriegs unbeirrt an einem „Siegfrieden“ festhielt. Dass dieses Aufflackern am äußeren politischen Rand keine „Eintagsfliege“ war, zeigt die langjährige Zugehörigkeit in der Deutsch-Nationalen Volkspartei (DNVP), die teilweise antisemitische Überzeugungen vertrat und im März 1933 Koalitionspartner der NSDAP wurde. Als weitere rechtsextreme Organisation, der von Bahrfeldt angehörte, ließe sich der „Stahlhelm. Bund der Frontsoldaten“" anführen, der ebenfalls große Schnittmengen mit der Hitler-Partei aufwies. Zu Beginn der Nazi-Herrschaft wurde der „Stahlhelm“ in die Reserve der „Sturmabteilung“" (SA) überführt, sodass der greise Münzforscher sich in diesem NS-Verband wiederfand. Dass er dem heraufziehenden Nationalsozialismus mit Sympathien begegnete, lässt sich auch daran ablesen, dass er am 5. März 1933 die „Erklärung deutscher Universitäts- und Hochschullehrer" unterschrieb, die sich für die Regierung Adolf Hitler und gegen „marxistisch-bolschewistische Einflüsse“ einsetzte. ${ }^{40}$ Seine Verbundenheit mit der Regierung des „Dritten Reichs“ drückte er auch an anderer Stelle aus. ${ }^{41} \mathrm{Am}$ 11. April 1936 verstarb der 80-Jährige in Halle an der Saale, wo er die letzten 15 Jahre gelebt hatte. ${ }^{42}$

\footnotetext{
${ }^{34} \mathrm{MvB}$ (1919), S. $73 \mathrm{f}$.

${ }^{35}$ Max von Bahrfeldt an den Dekan der Philosophischen Fakultät der Universität Halle-Wittenberg am 20.10.1922. In: UAHW 4080.

${ }^{36}$ MvB (1930b); Wannack (2007).

${ }^{37}$ Gelehrte Gesellschaften und Vereine (1924), S. 128.

${ }^{38}$ Vierter deutscher Münzforschertag zu Halle a. S. (1925); MvB (1925a); MvB (1926d).

${ }^{39} \mathrm{MvB}(1933 / 34)$.

${ }^{40}$ Eberle (2002), S. 38.

${ }^{41} \mathrm{MvB}$ (1935), S. 38.

${ }^{42}$ Gaettens (1936), S. 410; Gaettens (1937), S. 2875 f.
} 


\section{Experte für das niedersächsische Münzwesen und das moderne „Notgeld“}

Obwohl der Numismatiker aus der Uckermark stammte, konzentrierte sich sein Interesse auf das damalige Niedersachsen und dessen Währungssystem, genauer gesagt auf die sog. „Kipper- und Wipperzeit“" im 17. Jahrhundert, eine Epoche der Spekulanten und Münzverschlechterungen. Diese Vorliebe rührte vor allem daher, dass er als Offizier in Bremen, Stade und Harburg stationiert und seine Familie früher in der Nähe von Hildesheim ansässig gewesen war. ${ }^{43}$ Es ist deshalb nicht verwunderlich, dass 1879 sein erster größerer Beitrag „Die Münzen der Stadt Stade“ behandelte. ${ }^{44}$ Weitere Schriften untersuchten die Herzogtümer Bremen und Verden", ${ }^{45}$ die Lüneburgischen Lande ${ }^{46}$ und das Bistum Ratzeburg. ${ }^{47}$ Die langjährige Beschäftigung mit ähnlich gelagerten Fragestellungen schlug sich in unzähligen lokalen und regionalen Veröffentlichungen nieder, die verschiedene Kommunen mit ihren Münzprägestätten, regierenden Herzögen oder Bischöfen vom Spätmittelalter bis zur Französischen Revolution erforschten. Aus den akribischen Vorarbeiten entstand der Plan, das Material zur Geldgeschichte des gesamten Landes im 16. und 17. Jahrhundert in einem dreiteiligen Werk zusammenzutragen. ${ }^{48}$ In Anlehnung an die grundlegende Publikation von Johann Christoph Hirsch (16981780), „Des Teutschen Reichs Münzarchiv““ ${ }^{49}$ gab von Bahrfeldt seinem Unternehmen den Titel „Niedersächsisches Münzarchiv (1551-1625)“, das letztendlich in vier großen Quartbänden mit 2300 Urkunden, Briefen, Gutachten, Berichten und Protokollen in einem Umfang von 2196 Seiten in den Jahren 1927 bis 1930 im heimischen RiechmannVerlag erschien. ${ }^{50}$

Den zeitlichen Ausgangspunkt der Edition bildete die in Augsburg von Kaiser Karl V. beschlossene Münzordnung, das Ende markierte 75 Jahre später der Niedergang der niedersächsischen Kreis- und Probationstage infolge des 30-jährigen Krieges. Allein der erste Band enthielt eine große Menge an Informationen über die münzberechtigten Städte, die benutzten Archive, Münzkabinette und Sammlungen, die gedruckten Münzordnungen, Edikte und Mandate, die Münz- und Probiergewichte, zahlreiche Münzabbildungen sowie Erläuterungen zu den abgebildeten Geldstücken, deren Opulenz beeindruckend wirkt: Portugalöser, Dukaten, Goldgulden, ganze, halbe, viertel Taler, Markstücke, halbe Mark, Verding, Fürstengroschen, Silbergroschen, Meißnische Groschen, Schneeberger, Dreimatthiergroschen, Zwölfergroschen, Spitzgroschen, Mariengroschen, Doppelschillinge, einfache und halbe Schillinge, Sechslinge, Dreier, Dreipfenniggroschen, Grote, Schware, Körtlinge, diverse Arten von Pfennigen, Hellern, Scherfen usw. Neben etwa 550 Dokumenten zu den Finanzen konnten im damaligen Niedersachsen für die Jahre von 1551 bis 156820 verschiedene Münzmeister, Probierer und Wardeine nachgewiesen werden. Die Bände 2-4 hatten ein ähnliches Profil und einen vergleichbaren Umfang. In dem Opus Magnum legte der Autor nicht nur Zeugnis der umfassenden, rund 50 Jahre andauernden Auswertung der Akten des Niedersächsischen Kreisarchivs ab, sondern stellte eine Fülle von geldgeschichtlichen und münzrechtlichen Nachrichten der Öffentlichkeit zur Verfügung. Insgesamt ließen die

\footnotetext{
${ }^{43}$ Gaettens (1936), S. 410.

${ }^{44} \operatorname{MvB}(1879)$.

${ }^{45} \mathrm{MvB}$ (1892).

${ }^{46} \mathrm{MvB}(1893)$.

${ }^{47} \operatorname{MvB}(1911 / 13)$.

${ }^{48} \mathrm{MvB}$ (1927a), S. 1272.

${ }^{49}$ Hirsch (1756-1768).

${ }^{50}$ MvB (1927-1930), Bd. 1-4.
} 
vielfältigen Beziehungen erkennen, dass „die Reichsleitung völlig versagte, Ordnung im deutschen Münzwesen zu schaffen und es auf eine gesunde Basis zu stellen." ${ }^{\text {(51 }}$

Jahrzehntelang spielten die Geldstücke der Stadt Hildesheim eine wichtige Rolle im Leben des preußischen Offiziers. Spätestens seit er 1913 seinen Wohnsitz in die Kommune verlegt und die Verwaltung der Münzsammlung im Roemer-Museum übernommen hatte, ${ }^{52}$ kristallisierte sich die Überlegung heraus, das Thema in einer Monografie zu untersuchen. Der Erste Weltkrieg, die Professur in Halle und nicht zuletzt wirtschaftliche Schwierigkeiten verhinderten eine Realisierung des Vorhabens. Erst 1935 gelang es dem Oberbürgermeister von Hildesheim, die nötigen Finanzmittel bereitzustellen und den betagten Numismatiker als Bearbeiter einer Hildesheimer Münzgeschichte zu gewinnen. Über Vorarbeiten an dem Projekt ist von Bahrfeldt infolge seines Todes nicht mehr hinausgekommen, sodass es sein Vermächtnis bildete und erst durch den Geheimen Hofrat Heinrich Buck (1866-1939) abgeschlossen werden konnte. Die Studie untersuchte die Geldgeschichte des Ortes von 1096 bis 1772 einschließlich der Münzgebäude, Münzverwaltungen, Münzbetriebe, Stadtwappen sowie zirkulierende fremde Währungen und ging auf Medaillen, Zeichen sowie benutzte Quellen ein. ${ }^{53}$

In den letzten Jahren seines Wirkens richtete sich das Interesse des ehemaligen Generals verstärkt auf das geprägte „Notgeld“ des Ersten Weltkrieges. „Notgeld“ galt in Krisenzeiten als Ersatzwährung für die offiziellen Zahlungsmittel. Im „Numismatischen Literatur-Blatt“ berichtete er regelmäßig darüber und reflektierte, dass ,,das wissenschaftliche Niveau der überwiegenden Mehrzahl der Sammler doch recht niedrig“ sei. ${ }^{54}$ Für die Abfassung einer kleinen Arbeit über Hamm in Westfalen gab er als Grund nicht nur die weit überdurchschnittliche Bedeutung der Serie an, sondern auch denjenigen, ,daß aus den Akten doch mehr [...] herauszuholen ist, als aus einer öden Zusammenstellung von geringfügigsten Stempelvarianten. ${ }^{\text {" }} 551930$ widmete er sich der Provinz Ost- und Westpreußen, deren etwa 20 Emissionsorte behandelt und auf vier Tafeln illustriert wurden. Wie der Autor verdeutlichte, verloren die preußischen Stellen allmählich die Herrschaft über das Geldwesen, ehe die Inflation 1923 auch dieser Episode ein Ende bereitete. ${ }^{56}$ Eine weitere Veröffentlichung galt dem Freistaat Baden, einem Bezirk, in dem 35 Orte von Adelsheim bis Zell im Wiesental auf das ,Notgeld“" zurückgriffen. Neben der Auswertung der Originalakten des Badischen Innenministeriums wurde Wissenswertes über Prägeanstalten, Stempel, Metalle, Schrötlinge, Durchlöcherung und Geheimzeichen geboten. ${ }^{57}$ Eine Studie zur Provinz Schlesien 1917-1921 stellte seine letzte Untersuchung zu dieser Materie dar. Laut Verfasser griffen 34 Kreise, Städte, Ämter, Gemeinden und Sparkassen in Schlesien zur Herstellung von „Notgeld“, allerdings seien die Akten unvollständig. Die Herausgabe von Sondermarken seitens der Städte Frankenstein, Münsterberg, Neumarkt, Strehlen, Wansen und Wohlau sei ungewöhnlich gewesen, da sie mit stillschweigender Duldung der Aufsichtsbehörden umgelaufen seien, ohne dass dafür eine Genehmigung eingeholt worden wäre. ${ }^{58}$

\footnotetext{
${ }^{51} \operatorname{MvB}(1927-1930)$, Bd. 4, Vorwort S. III.

${ }^{52} \mathrm{MvB}$ (1914).

${ }^{53}$ Buck / † von Bahrfeldt (1937).

${ }^{54}$ MvB (1927b), S. 2183; vgl. MvB (1926b).

${ }^{55}$ MvB (1928b), Zitat S. 2235; vgl. MvB (1928a).

${ }^{56} \mathrm{MvB}$ (1930b).

${ }^{57} \operatorname{MvB}(1932 a)$.

${ }^{58} \operatorname{MvB}(1935 a)$.
} 


\section{Numismatiker der römischen Republik}

Ausgangspunkt der Leidenschaft für die Geldstücke der Antike bildete die Beschäftigung mit Theodor Mommsens (1817-1903) „Geschichte des römischen Münzwesens“ ${ }^{59}$ Der berühmte Althistoriker hatte 1860 in dem Werk „die erste systematische Erörterung möglicher Kriterien für eine chronologische Einordnung der republikanischen Münzen“ vorgelegt. ${ }^{60}$ Nach eigener Aussage zeigte von Bahrfeldt sich schon in seiner Jugend überrascht, wie es dem späteren Literaturnobelpreisträger gelang, aus relativ wenig und teilweise unsicherem Material richtige Schlüsse zu ziehen. Aus dieser Beobachtung resultierte die persönliche Konsequenz, für die metrologischen und chronologischen Forschungen das Gewicht der einschlägigen Münzen zweifelsfrei zu bestimmen. Im zeitlichen Kontext wird man die Untersuchungen des preußischen Offiziers an der Schnittstelle von antiquarischen Beschreibungen der Geldstücke einerseits und moderner Numismatik andererseits zu verorten haben, wie er für die zweite Hälfte des 19. Jahrhunderts kennzeichnend war. Von Bahrfeldt stand zweifellos in der Tradition von Mommsen, konzentrierte sich aber speziell auf das Währungssystem der römischen Republik und zog nicht, wie sein virtuoses Vorbild, alle Quellengattungen der Altertumswissenschaften zur historischen Analyse heran.

Bereits 1875 erfolgte der dreimonatige Besuch der Bestände des Pariser „Cabinet des médailles“" und der Firma „Rollin \& Feuardent“, bei der die Wägungen der antiken Geldstücke im Vordergrund standen. Dabei lernte er den international bekannten französischen Münzforscher Henry Cohen (1806-1880) ${ }^{61}$ kennen und schätzen. Der ehemalige Novize beschrieb rückblickend die Koryphäe als „hageren, etwas wortkargen, alternden Herrn“. ${ }^{62}$ Cohen machte sich hingegen über die so genannte „Wägungsmanie“ des jungen Deutschen lustig. ${ }^{63}$ Bahrfeldt betonte jedoch zu Recht die Bedeutung der exakten Gewichtsangabe sowie des Erhaltungszustandes, um zu verlässlichen Aussagen über den Durchschnittswert des geprägten Metalls gelangen zu können. Der Tod seines Schwiegervaters, des schleswig-holsteinischen Geheimen Staatsrats Karl Friedrich Lucien Samwer (1819-1882), ${ }^{64}$ markierte eine weitere Zäsur für den Numismatiker. Beide Männer hatten sich 1875 über die gemeinsame Münzleidenschaft kennengelernt, später intensiv korrespondiert und beschlossen, zusammen eine Studie zu den Anfängen des Währungssystems des Imperium Romanum zu verfassen. Dieses Vorhaben war bereits in Angriff genommen worden, als Samwer starb und seine antiken Geldstücke dem Schwiegersohn vermachte, sodass dieser insgesamt über die größte Kollektion von Zahlungsmitteln der römischen Republik überhaupt verfügte, die nach eigener Einschätzung nur von der Ailly'schen Sammlung noch übertroffen wurde. ${ }^{65}$ Bereits vorhandene Manuskriptteile ergänzte er und gab im folgenden Jahr eine Abhandlung zur Geschichte des ältesten Münzwesens der Tiber-Stadt heraus, die in fünf Abschnitten das Thema von 350 bis $201 \mathrm{v}$. Chr. beleuchtete und in Einzelfragen von Mommsens Darstellung abwich. ${ }^{66}$

\footnotetext{
${ }^{59}$ Mommsen (1860); Dressel (1904); Geldgeschichte vs. Numismatik (2004).

${ }^{60}$ Hollstein (2004), S. 188.

${ }^{61}$ Schubert (2012b).

${ }^{62} \operatorname{MvB}$ (1931a), S. 2490; MvB (1933/34), S. 742 f.

${ }^{63} \mathrm{MvB}(1923)$, S. VII.

${ }^{64}$ Steindorff (1890).

${ }^{65}$ Die Sammlung von Pierre Philippe Bourlier Baron d'Ailly (1794-1877) im Château d'Ailly bei Roanne an der Loire (Frankreich) soll rund 14.000 bzw. 17.300 Münzen der römischen Republik umfasst haben; vgl. MvB (1876b), S. 355; MvB (1919), S. 73; Bourlier d‘Ailly (1866).

${ }^{66} \mathrm{MvB}(1883)$.
} 
Der Sammler und engagierte Publizist wurde 1885/86 durch das zweibändige Werk von Ernest Babelon (1854-1924) ${ }^{67}$ inspiriert oder, vielleicht besser gesagt, angestachelt, das den „monnaies de la république romaine“ gewidmet war, aber die traditionelle alphabetische Ordnung beibehielt. ${ }^{68}$ In drei großangelegten Nachträgen, denen Besuche in zahlreichen Sammlungen Europas zugrunde lagen, unternahm es der preußische Offizier in den Jahren 1896/97, 1900 und 1918, auf eine Vielzahl von Lücken und Irrtümern des Pariser Fachmanns hinzuweisen. ${ }^{69}$ Dabei mögen gegenseitige Antipathien zwischen Deutschen und Franzosen, beginnend mit den Napoleonischen Kriegen, eine wesentliche Rolle gespielt haben, ${ }^{70}$ jedenfalls sprach der Deutsche despektierlich davon, ,den zweibändigen Augiasstall“" säubern zu wollen. ${ }^{71}$ Zweifellos offenbarte sich in diesen überaus umfangreichen Korrekturen neben methodischen Überlegungen auch ein persönlicher Wesenszug, der sich auch immer wieder im „Numismatischen LiteraturBlatt" niederschlug: ein Streben nach absoluter Korrektheit, die Neigung, andere zu belehren, und nicht zuletzt beharrliche Rechthaberei. Jeder noch so kleine Fehler wurde dem französischen Kollegen nachgewiesen und „um die Ohren gehauen“. Beispielsweise rechnete er jede Jahreszahlenangabe von Babelon nach und kreidete ihm allein im ersten Band unzählige falsche Werte minutiös an, die bei der Übertragung von der römischen Chronologie (ab urbe condita) auf die moderne Zeitrechnung (nach Christus) unterlaufen waren. ${ }^{72}$ Dass er sich mit diesem Verhalten jenseits des Rheins keine Freunde machte, war wohl auch eine bewusste und politisch motivierte Entscheidung. Insgeheim fand der Preuße jedoch die großen Repertorien westlicher Nachbarn „,deprimierend“: „Wir Deutsche [...] wollen etwas ganz Tadelloses liefern, bleiben damit aber vor lauter Bedenklichkeit und Umständlichkeit in den Anfängen stecken und kommen nicht zum Ziele“. ${ }^{73}$

Die Hassliebe zwischen den beiden Münzexperten setzte sich bis zum Tod von Babelon 1924 fort. In einem kurzen Nachruf ging der pensionierte General auf seinen annähernd gleichaltrigen Kontrahenten ein. Er lobte dessen zweibändiges Werk über die römischen Geldstücke als ,unentbehrliches Handbuch“. Ansonsten würdigte er die Leistungen des Verstorbenen auf numismatischem Gebiet und versicherte, dass seine Verdienste unvergessen bleiben werden. Bewegte sich die Todesanzeige bis hierhin in den Bahnen des Genres, so erhielt der Nekrolog im Schlussteil eine für von Bahrfeldt typische nationale Richtung: ,,Vergessen wollen wir aber auch niemals seine gehässige und feindselige Gesinnung allem Deutschen und vor allem den deutschen Gelehrten und der deutschen Wissenschaft gegenüber. War Babelon doch der größte Chauvinist und Hetzer und ist doch vor allem auf sein Betreiben das noch heute im feindlichen Auslande unvermindert bestehende Bestreben zurückzuführen, die deutsche Wissenschaft gänzlich zu boykottieren. ${ }^{674}$ Mit dieser Einschätzung stand der Hallenser Honorarprofessor nach dem Ersten Weltkrieg keineswegs allein im deutschen Kollegenkreis. $^{75}$

\footnotetext{
${ }^{67}$ Regling (1924c); Schubert (2012a).

${ }^{68}$ Babelon (1885/86).

${ }^{69} \operatorname{MvB}$ (1896/97); (1900a); (1919).

${ }^{70}$ Vgl. MvB (1900b), S. 1037; MvB (1919), S. 74.

${ }^{71} \mathrm{MvB}(1900)$, S. 2.

${ }^{72}$ MvB (1896/97), hier Bd. 29, Anlage 5, S. 148-150.

${ }^{73}$ MvB (1902), S. 1092.

${ }^{74}$ MvB (1924).

${ }^{75}$ Regling (1924b), S. 399; Regling (1924c), S. 404. Die Hallenser Philosophische Fakultät warf Babelon ein „hochmütiges Ignorieren der ausländischen Literatur“ vor; vgl. Schreiben an den Preußischen Minister für Wissenschaft, Kunst und Volksbildung am 30.11.1921. In: UAHW 4080.
} 
Mit den großen Editionen von Cohen und Babelon setzte sich von Bahrfeldt auch 1923 in einer Monografie auseinander, in der er en détail die Früchte seiner Sammlung römischer Goldmünzen sowie der von ihm zur Meisterschaft entwickelten Technik der Gipsabgüsse inklusive der exakten Wägungen in Gramm zwei Stellen nach dem Komma präsentierte. Für die Publikation hatte er nahezu alle bedeutenden Aufbewahrungsstätten in Europa besucht und versucht, Klarheit über die verwirrende Anzahl von insgesamt 2.478 Geldstücken aus 57 öffentlichen und 50 privaten Kollektionen zu gewinnen, wobei das Nachspüren von Herkunft und Verbleib interessanter Münzen für ihn einen besonderen Reiz ausübte. Eine aus der Systematik entwickelte Synthese im Geiste Mommsens lag ihm hingegen weniger. In einer Rezension bezeichnete der Direktor des Münzkabinetts Berlin, Kurt Regling (1876-1935), das Buch als Werk „des bekanntesten und fruchtbarsten Münzforschers auf römisch-republikanischem Gebiete". ${ }^{76}$

Typisch für den allseits interessierten Numismatiker blieb, dass er immer wieder in Nachträgen versuchte, an frühere Studien anzuknüpfen und ihre Ergebnisse zu aktualisieren. Von den zahlreichen Veröffentlichungen in einschlägigen Journalen ragen insbesondere diejenigen in der Wiener „Numismatischen Zeitschrift" und der Berliner „Zeitschrift für Numismatik“ heraus. In Auseinandersetzung mit den Publikationen des erwähnten Barons d'Ailly und Julius Friedländers (1813-1884), dem Direktor des Königlichen Münzkabinetts zu Berlin, widmete er sich ,überprägten Münzen aus der Zeit der römischen Republik“، ${ }^{77}$ In dem Aufsatz zu den Münzen der Flottenpräfekten des Marcus Antonius ging er einer bekannten Quellengattung nach, sortierte zahlreiche Fälschungen aus und konnte die Gruppe dieser Geldstücke auf 179 eingrenzen. Ferner kommentierte er sie, indem er seine Befunde vor allem mit Babelons Standardwerk verglich, was erneut zu einer langen Liste von festgestellten Mängeln führte. ${ }^{78}$ Eine weitere Druckschrift dieser Art galt der letzten Kupferprägung der römischen Republik. ${ }^{79}$ Auch in ausländischen Fachblättern legte der Experte die Resultate seiner Recherchen in längeren Artikeln nieder ${ }^{80}$ Für eine Untersuchung des antiken campanischen Geldes für die renommierte Zeitschrift „Rivista Italiana di Numismatica“ erhielt er sogar den ersten Preis des „Concorso Gnecchi“ verliehen. ${ }^{81}$ Außerdem nahm der deutsche Offizier an den vom 3. bis 7. April 1903 abgehaltenen Sitzungen der numismatischen Sektion des II. Internationalen Historikerkongresses in Rom teil. ${ }^{82} 1910$ erfuhr er von britischer Seite hohe Anerkennung, als er gebeten wurde, das dreibändige amtliche Katalogwerk „Coins of the Roman Republic in the British Museum“ mit Korrektur zu lesen. $^{83}$

Wie man an dieser stattlichen Liste von Publikationen und Auszeichnungen ablesen kann, gehörte von Bahrfeldt zweifellos seit dem frühen 20. Jahrhundert zu den internationalen Gelehrten, die für die Numismatik der römischen Republik und den Übergang zur Kaiserzeit das meiste Prestige vorweisen konnten. Dies unterstreichen seine freundschaftlichen Beziehungen zu dem Frankfurter Kommerzienrat Ernst Justus Haeberlin (1847-1925), der auf verwandtem Gebiet forschte. Ihm stellte er seine private Münzsammlung für dessen Werk zum „Aes grave“ zur Verfügung, unternahm mit ihm

\footnotetext{
${ }^{76}$ Regling (1924a), S. 375.

${ }^{77} \mathrm{MvB}(1895)$.

${ }^{78} \mathrm{MvB}(1905)$.

${ }^{79} \operatorname{MvB}(1909 b)$.

${ }^{80} \operatorname{MvB}(1904 a)$.

${ }^{81}$ MvB (1899/90). Der Dekan der Philosophischen Fakultät der Universität Halle-Wittenberg an den Preußischen Minister für Wissenschaft, Kunst und Volksbildung am 30.11.1921. In: UAHW 4080.

${ }^{82}$ MvB (1904b); vgl. Erdmann (1987), S. 38-63.

${ }^{83}$ Gaettens (1936), S. 411.
} 
mehrere Studienreisen nach Italien und gab zusammen mit Haeberlins Familie einen Gedenkband aus seinem Nachlass heraus. ${ }^{84}$ Dass der preußische Offizier in der Regel „verwandten Seelen“ Unterstützung zuteilwerden ließ, zeigt auch die Bereitstellung von numismatischem Material für die „Geschichte der römischen Kupferprägung“ des niedersächsischen Archäologen Heinrich Willers (1870-1915). ${ }^{85}$ Wie dieser schrieb, war er ob dieser vielfältigen Protektion „Herrn Generalmajor Bahrfeldt“ in Rastenburg $\mathrm{zu}$,innigem Dank“ verpflichtet. ${ }^{86}$ Das Interesse für das Geld des Imperium Romanum hinderte ihn jedoch nicht daran, seine stattliche Kollektion von Münzen der römischen Republik im Jahr 1919 an den Gleichgesinnten Otto Hager (1853-1937) zu veräußern. ${ }^{87}$ 1925 kaufte das Kestner-Museum in Hannover diese größte Privatsammlung von Zahlungsmitteln der römischen Republik nördlich der Alpen für 40.000 Mark auf. So verfügt diese öffentliche Einrichtung in Niedersachsens Hauptstadt heute über rund 4.000 Münzen aus der antiken Epoche. ${ }^{88}$

\section{Kriegsverbrecher Nr. 10}

Dass Max von Bahrfeldt im Ersten Weltkrieg zu jenen altertumswissenschaftlich aktiven Gelehrten gehörte, die in die blutigen Geschehnisse involviert waren, ist bislang übersehen oder übergangen worden. ${ }^{89}$ Der reaktivierte General befehligte Anfang August 1914 eine Division, also einen militärischen Großverband. Aus dem Konzentrationsgebiet um Schleiden in der Nordeifel wurde der Vormarsch in Richtung Westen angetreten, am 14. August die belgische Grenze überschritten, schließlich über Spa und Lüttich Charleroi erreicht. Zu den dortigen Ereignissen hieß es in der Veröffentlichung des amtlichen Reichsarchivs: „Der Vormarsch [...] der 19. Reserve-Division war in den planmäßig zur Verteidigung eingerichteten Vororten von Charleroi zum Stocken gekommen. Ihre Vorhut sah sich in einen erbitterten Straßenkampf verwickelt, in dem jedes Haus einzeln gestürmt werden musste, ehe der Widerstand der fanatischen Einwohnerschaft gebrochen werden konnte. ${ }^{190}$ Was sich im wallonischen Industriezentrum am 22. und 23. August 1914 abgespielt hat, wurde in der Folge zwischen den Kriegsparteien kontrovers eingeschätzt. Die deutsche Seite hielt die eigene Vorgehensweise für aufgezwungen und völkerrechtskonform. Auch Kommandeur von Bahrfeldt vertrat die Auffassung, dass keine regulären feindlichen Soldaten gekämpft hätten, sondern Einwohner Charlerois und ,belgische Franktireure“. 91

Nach Beendigung des Ersten Weltkrieges räumten die Artikel 228-230 des Versailler Vertrages den alliierten Mächten das Recht ein, die Auslieferung von denjenigen Deutschen zu verlangen, die Verbrechen gegen feindliche Staatsangehörige oder fremdes Eigentum begangen hatten. ${ }^{92}$ Daraufhin reichten die Westalliierten am 7. Februar 1920 Listen beim deutschen Reichskanzler ein, die allgemeine Vorwürfe gegen eine Reihe von belasteten Personen enthielten. Als Nr. 10 des belgischen Auslieferungsgesuchs war von Bahrfeldt angeführt, dem man „Atrocités de Charleroi, Août 1914“vorwarf. Um eine Übergabe von potenziellen Kriegsverbrechern zu vermeiden, bot die

\footnotetext{
${ }^{84}$ Haeberlin (1910), Bd. 1, S. XVIII; MvB (1925b); MvB (1929).

${ }^{85}$ MvB (1923), S. IX; vgl. Regling (1922).

${ }^{86}$ Willers (1909), Einleitung, S. VII.

${ }^{87}$ Gaettens (1936), S. 414.

${ }^{88}$ Berger (1989), S. 6-8.

${ }^{89}$ Von Ungern-Sternberg (2017).

${ }^{90}$ Reichsarchiv (1925), S. 357.

${ }^{91}$ MvB (1935b), S. 18.

${ }^{92}$ Schwengler (1982).
} 
Reichsregierung an, den Beschuldigten den Prozess zu machen. Am 22. Oktober 1923 wurde das Verfahren vor dem Reichsgerichtshof in Leipzig gegen von Bahrfeldt eingestellt, weil sein Verhalten in Charleroi von den gesetzlichen Bestimmungen gedeckt gewesen sei. ${ }^{93}$ Angesichts dieses Freispruchs, der kein Einzelfall war, wird man wohl bilanzieren können, dass „die obersten Organe der deutschen Strafrechtspflege mit der Verfolgung der von Deutschen im Ersten Weltkrieg begangenen Vergehen oder Verbrechen nicht ernst gemacht haben."

Zwei Jahre später eröffnete die Justiz in der belgischen Stadt Mons ein neues Verfahren gegen von Bahrfeldt und andere. Am 9. Oktober 1925 wurde er als Oberbefehlshaber in Charleroi wegen Mordes an 29 Menschen, Brandstiftung und Diebstahls ohne Verteidigung in Abwesenheit zum Tode verurteilt. Zweifellos handelte es sich dabei eher um einen symbolischen Akt als um eine Maßnahme zur realen Strafverfolgung. In Halle, wo der General a. D. als Professor für Münzkunde tätig war, wurde die Verurteilung durch die Presse verbreitet und löste bei dem Betroffenen höchste Empörung aus. In dem Artikel „Meine Kriegsverbrechen“, der in der Halleschen Saale-Zeitung vom 18. Oktober 1925 erschien, stellte von Bahrfeldt seine Sicht der Dinge in Charleroi dar. ${ }^{95}$ Über die Bewohner der belgischen Industriestadt urteilte er rückblickend: „Die untere Arbeiterbevölkerung ist ein Gemisch von Wallonen, Flamen, Deutschen und fremdstämmigen Einwanderern, beeinflußt durch die niedere katholische Geistlichkeit, verkommen infolge des Mangels jeglicher sozialer Fürsorge, dem Alkohol verfallen und infolgedessen verkümmert, der Wallone leicht erregbar, hinterlistig, ein gefährlicher Feind im Rücken der Armee." Zu den Kampfhandlungen kommentierte er: „Häuser, aus denen geschossen wurde, verfielen der Vernichtung, sie gingen in Flammen auf. Zivilpersonen, die mit der Waffe in der Hand betroffen, wurden erschossen. Dabei hat manchen Unschuldigen zweifellos dasselbe Los getroffen, denn der erbitterte Straßenkampf peitschte die Leidenschaft auf. [...] Alte und junge Männer, selbst Frauen beteiligten sich am Kampfe. Waffen aller Art wurden von ihnen verwendet, vom Browning und modernen Militärgewehr bis zur großkalibrigen Schrotflinte. “96 Wie aus dem Leipziger Schriftsatz von 1923 ersichtlich wird, hatte von Bahrfeldt im August 1914 Feldkriegsgerichte einsetzen und Todesurteile gegen Zivilisten sofort vollstrecken lassen. ${ }^{97}$ Außerdem verhängte er eine Strafe von 10 Millionen Franken und oktroyierte die Bereitstellung von 160 zweispännigen Fahrzeugen mit Lebensmitteln und Bedarfsartikeln aller Art. ${ }^{98}$

Der „Kriegsverbrecher Nr. 10“ erhielt nach eigenen Angaben 1925 viel Zuspruch aus den national eingestellten Medien sowie von seinem ,hochverehrten Gönner", Herzog Bernhard zu Sachsen-Meiningen (1851-1928), gegen Beschuldigungen „der unerhörten belgischen Schandjustiz“. ${ }^{99}$ Als „Schmähungen“ bezeichnete Artikel von linken „Revolverblättern“ und Privatleuten im eigenen Land wurden von ihm verurteilt. Gegen die in Allenstein erscheinende „Gazeta Olszynska“ erhob er sogar Klage, woraufhin der Hauptschriftleiter der Zeitung, Kasimir Jarozyck, am 31. März 1926 durch das Schöffengericht der ostpreußischen Garnisonsstadt wegen Beleidigung zu drei Monaten Gefängnis verurteilt wurde. ${ }^{100}$ In einem erbosten Briefwechsel mit dem

\footnotetext{
${ }^{93} \mathrm{MvB}$ (1935b), S. $10 \mathrm{f}$.

${ }^{94}$ Schwengler (1982), S. 359.

$95 \mathrm{Vgl}$. MvB (1935b), S. 15.

${ }^{96}$ Ebd., S. 17.

${ }^{97}$ Ebd., S. 10 f.

${ }^{98}$ Ebd., S. 20 f.

${ }^{99}$ Ebd., S. 12 f.

${ }^{100}$ Ebd., S. 12.
} 
Auswärtigen Amt des Deutschen Reiches 1925/26 verlangte er, dass seine Ehre als Offizier geschützt und die vollständige Reisefreiheit wiederhergestellt werden müsse. ${ }^{101}$ Wie tief der Stachel der Verurteilung als Kriegsverbrecher saß, lässt sich daran erkennen, dass er über 20 Jahre nach den Ereignissen von Charleroi eine Propagandaschrift veröffentlichte, in der er mittels abgedruckter Zeugenaussagen und anderer Dokumente seine Unschuldsbehauptung zu ,beweisen“ suchte. Rückblickend formulierte der fast 80-Jährige zu den Ereignissen im August 1914 starrköpfig: „Die wider alles Völkerrecht und mit der Waffe in der Hand uns entgegengetretenen Banditen sind erschossen worden und haben nur ihren gerechten Lohn erhalten. Die von den Freischützen besetzten Häuser, aus denen geschossen worden war, und nur diese, sind im Kampfe in Brand gesteckt worden. Und der mir vorgeworfene Diebstahl? Wenn damit die 10 Millionen Geldbuße und die Sachlieferungen gemeint sind, dann tut es mir leid, daß ich der reichen verbrecherischen Stadt nicht eine noch höhere Buße auferlegt habe! Nicht von mir sind ,atrocités ${ }^{\star}$ ausgegangen, sondern von dem städtischen und anderen Gesindel, das dadurch großes Leid über die Stadt gebracht hat.“" ${ }^{102}$

Der deutsche Angriff im August 1914 ist mittlerweile von Historikern verschiedener Nationalitäten gründlich untersucht worden. Dabei stand weniger die Frage im Zentrum, ob es sich um einen verbotenen Angriffskrieg gegen das neutrale Belgien handelte, sondern inwieweit die ortsansässige Bevölkerung von den Kampfhandlungen betroffen war. Charleroi und General von Bahrfeldt spielten dabei eine untergeordnete Rolle. ${ }^{103}$ Trotz schlechter Quellenlage kann als gesichert gelten, dass bei dem Vormarsch Häuser in Brand gerieten und einstürzten, belgische Zivilisten als menschliche Schutzschilde missbraucht wurden, Granatbeschuss und Gewehrfeuer zahlreiche Opfer forderten und es zu Exekutionen durch deutsche Einheiten gekommen ist. Dieser Befund überrascht nicht, da ein Feldzug in einer städtischen Umgebung, der strategisch unter höchstem Zeitdruck stattfand (Schlieffen-Plan), Opfer auf Seiten der belgischen Bevölkerung fordern musste. Ohne auf Einzelheiten einzugehen, bleibt festzuhalten, dass von Bahrfeldt in seiner Darstellung nur die einseitige Position als ranghoher deutscher Offizier gelten ließ, seine Befehle für völkerrechtskonform hielt und abweichenden Meinungen bis zu seinem Tod mit verächtlicher Zurückweisung begegnete.

\section{Professor für Münzkunde in Halle an der Saale}

Im fortgeschrittenen Alter von 55 Jahren erhielt der Berufsoffizier die Gelegenheit, einen akademischen Titel zu erwerben. Der Althistoriker Max Strack (1867-1914) ${ }^{104}$ schlug der Philosophischen Fakultät der Großherzoglichen Universität Gießen im November 1911 vor, ihn zum Doktor ehrenhalber (Dr. honoris causa) zu ernennen. Beide Numismatiker kannten sich wohl nur aus der Fachliteratur. ${ }^{105}$ Zur Begründung verwies Strack auf die hohe wissenschaftliche Bedeutung des Münzforschers und fügte seinem Antrag zur Bekräftigung ein Schriftenverzeichnis bei. ${ }^{106}$ Da sich die Gießener Philosophische Fakultät dem Gesuch anschloss, wurde dem „Königlich-Preußischen Generalleutnant" am 20. Dezember 1911 die Ehrendoktorwürde der mittelhessischen Alma

\footnotetext{
${ }^{101}$ Ebd., S. 30-37.

102 Ebd., S. 22.

${ }^{103}$ Horne / Kramer (2004); Lipkes (2007); Baldin / Saint-Fuscien (2012).

${ }^{104}$ Körte (1919).

${ }^{105}$ Vgl. MvB (1926a), S. 395.

${ }^{106}$ Max L. Strack an den Dekan der Gießener Philosophischen Fakultät, am 16.11.1911. In: Universitätsarchiv Gießen (UAGi), Phil., O 24.
} 
Mater verliehen, die ihm bestätigte, ein „,ausgezeichneter Kenner altrömischer Münzen“ zu sein. ${ }^{107}$ Mit der Verleihung dieses akademischen Titels war der Grundstein dafür gelegt, später mit der Ernennung zum Honorarprofessor Mitglied in einer deutschen Universität zu werden.

Durch die Bekanntschaft mit Richard Gaettens hatte der Ruheständler nach dem Ersten Weltkrieg wieder engere Beziehungen zu Halle an der Saale aufgenommen, einer damals etwa 200.000 Einwohner zählenden Stadt mit langer altertumswissenschaftlicher Tradition. Die Wurzeln der Münzkunde reichten bis ins Jahr 1738 zurück, als der Universalgelehrte Johann Heinrich Schulze (1687-1744) zu einem vierstündigen „Collegio über die Münzwissenschaft“ einlud. Bekannte Namen an der Hochschule waren aber auch Friedrich August Wolf (1759-1824) oder der von 1889-1902 an der Saale lehrende Althistoriker Eduard Meyer. ${ }^{108}$ Offenbar reizte den Pensionär die Aussicht, die Nachfolge des erwähnten Oskar Leuze an der Alma Mater Halensis zu übernehmen, der zwischen 1913 und 1919 in zwei Stunden pro Woche in die griechische und römische Numismatik eingeführt hatte. Von Bahrfeldt erklärte sich bereit, Anfang des Jahres 1922 seinen Wohnsitz in die Saale-Stadt zu verlegen. In der Universität sollte der 65Jährige im Laufe der folgenden Jahre mit den Althistorikern Ernst von Stern (18591924), Richard Laqueur (1881-1959), Paul Schnabel (1887-1947), Woldemar Graf von Uxkull-Gyllenband (1898-1939), Clemens Bosch (1899-1955) und Wilhelm Weber (1888-1948), den Altphilologen Karl Prächter (1858-1933), Otto Kern (1863-1942), Ernst Diehl (1874-1947) und Georg Wissowa (1859-1931) sowie den Klassischen Archäologen Georg Karo (1874-1963) und Herbert Koch (1880-1962) zusammenarbeiten. ${ }^{109}$

Zunächst hatten Ernst von Stern und Georg Karo ${ }^{110}$ die Ernennung von Bahrfeldts als Honorarprofessor für Münzkunde beantragt. Diesem Ansinnen schloss sich am 24. November 1921 die Fakultät an, und das Anliegen wurde eine Woche später an den Preußischen Minister für Wissenschaft, Kunst und Volksbildung in Berlin weitergeleitet. Zur Begründung hieß es, dass der General a. D. eine „wertvolle Kraft“ und ,anerkannte Autorität“ sei. Neben der Auflistung der wissenschaftlichen Verdienste, der Ehrenpromotion in Gießen 1911 und der Notwendigkeit, den scheidenden Leuze zu ersetzen, argumentierte die Fakultät: „Nach alledem ist Herr von Bahrfeldt in ungewöhnlicher Weise befähigt, eine Lücke an unserer Universität auszufüllen, die umso stärker empfunden wird, als wir über eine recht beträchtliche, aber noch nicht wissenschaftlich ausgeschöpfte Münzsammlung verfügen." ${ }^{\text {"111 }}$ Noch vor Weihnachten 1921 antwortete Berlin zustimmend und berief den Geldexperten zum Honorarprofessor für Münzkunde. ${ }^{112}$ Diese Entscheidung fiel umso leichter, als der 65-Jährige keine staatlichen Bezüge für seine universitäre Tätigkeit erhielt, sondern anscheinend hinreichend durch seine Militärpension abgesichert war. ${ }^{113}$ Er musste 6 Mark bezahlen sowie den Amtseid auf die Weimarer Reichsverfassung ablegen, außerdem wurden die Gremien

\footnotetext{
107 Ernennungsurkunde der Großherzoglichen Hessischen Ludwigsuniversität für Max Bahrfeldt zum Doktor ehrenhalber vom 20.12.1911. In: UAGi, Phil., O 24.

${ }^{108}$ Zimmermann (1980); Zimmermann (1991); Meißner (2002).

${ }^{109}$ Vgl. Prokoph (1985); 100 Jahre Archäologisches Museum in Halle 1891-1991 (1991); Geschichte der Altertumswissenschaften (2012); Catalogus Professorum Halensis, (Zugriffe Januar 2021).

${ }^{110}$ Lindenlauf (2016).

${ }^{111}$ Der Dekan der Philosophischen Fakultät der Universität Halle-Wittenberg an den Preußischen Minister für Wissenschaft, Kunst und Volksbildung am 30.11.1921. In: UAHW, 4080.

${ }^{112}$ Der Preußische Minister für Wissenschaft, Kunst und Volksbildung an die Universität Halle-Wittenberg am 23.11.1921. In: UAHW 4080.

113 Der Kurator der Universität Halle-Wittenberg an das Versorgungsamt der Universität am 29.9.1924. In: UAHW 4080.
} 
der Universität und die Lokalpresse informiert. ${ }^{114}$ Der dürftig ausgefüllte Personalbogen wurde vom neuen Mitglied des Lehrkörpers anscheinend erst im Spätsommer 1924 (!) abgegeben. ${ }^{115}$ Er wurde damit von einem General a. D. zu einem außerordentlichen Professor, der als Motivation angab, dass er aus der „Hilfswissenschaft der Geschichte“ eine selbstständige Disziplin machen wolle, welche die Geographie, Staatsrecht, Kunstwissenschaft, Volkswirtschaft, Medizin und viele andere Fächer fördern könne. ${ }^{116}$

In Halle hielt von Bahrfeldt Lehrveranstaltungen zur Münzkunde, meist einstündige Vorlesungen pro Semesterwoche. Als Hilfsmittel dienten ihm die reiche Bibliothek, eine ausgezeichnete, wohl an die 15.000 Stück umfassende Abguss-Sammlung alter Münzen sowie die Originale der Firma A. Riechmann \& Co., aber auch die Bestände im Archäologischen Institut, dem sog. „Robertinum“. ${ }^{117} \mathrm{Zu}$ seinen Schülern zählten die numismatisch orientierten Zöglinge des Althistorikers Wilhelm Weber, Paul L. Strack (1904-1941) ${ }^{118}$ und Waldemar Wruck (1902-1971). ${ }^{119}$ Strack z. B. besuchte bei dem pensionierten General die Veranstaltungen „Die Münzprägung Alexanders des Großen und seiner Nachfolger“ (WiSe 1925/26) oder „Aes grave romanum et italicum. Münzkunde des alten Afrikas und Spaniens“ (SoSe 1926). ${ }^{120}$ Dem Vater von Paul Strack, Max L. Strack, hatte von Bahrfeldt die erwähnte Ehrenpromotion in Gießen $1911 \mathrm{zu}$ verdanken. ${ }^{121}$ Praktisch bot er ein weit gestreutes Spektrum zu fast allen historischen Epochen an, das von „Deutsches Münzrecht, besonders im 16. und 17. Jahrhundert“ (SoSe 1931) über „Münzkunde der Völkerwanderungszeit“ (SoSe 1933) bis zu „Das deutsche Geld von 1914 bis jetzt" (WiSe 1933/34) reichte. ${ }^{122}$ Ein besonderes Anliegen war es dem Altmeister, „sein Fach“ im Lehrplan der deutschen Universitäten zu verankern. Seinen Schützlingen wollte er die Fähigkeit vermitteln, einen haltbaren Gipsabdruck eines Geldstücks herzustellen, um so jederzeit das in einer fremden Sammlung oder Umgebung angetroffene Material „mitnehmen“ und auszuwerten zu können. Er bezeichnete dieses als ,ein unentbehrliches Rüstzeug“ für den Münzgelehrten. ${ }^{123}$

Volle 27 Semester wirkte der Numismatiker in Halle. Sieht man von einer Anfrage für einen Archivbesuch 1926 ab, finden sich in seiner Personalakte keine Informationen über besondere Vorkommnisse. ${ }^{124}$ Bei dem 17. Deutschen Historikertag 1930 in seiner Wahl-Heimatstadt gehörte er zu den Teilnehmern, ohne ein Referat zu halten. ${ }^{125}$ Aus anderer Quelle ist zu erfahren, dass ihm 1931 aus Anlass seines 75. Geburtstags zahlreiche Ehrungen zuteilwurden, unter anderem eine stattliche Tabula gratulatoria. ${ }^{126}$ Auf seine positive Einstellung gegenüber dem heraufziehenden Nationalsozialismus wurde oben bereits hingewiesen (vgl. Abschnitt 2). Antisemitische Äußerungen liegen von ihm nicht vor. Dass er dem althistorischen Dozenten Clemens Bosch, der im „Dritten Reich“ wegen seiner jüdischen Ehefrau Johanna von der Hallenser

\footnotetext{
${ }^{114}$ Vgl. UAHW 4080; Presse-Notiz zu Max von Bahrfeldt (1922).

${ }^{115}$ Max von Bahrfeldt an den Kurator der Universität Halle-Wittenberg am 14.8.1924. In: UAHW 4080.

${ }^{116} \mathrm{MvB}$ (1926c), S. 506 und 508.

${ }^{117}$ MvB (1926c), S. 509; 100 Jahre Archäologisches Museum in Halle 1891-1991 (1991); Zimmermann (1980); Zimmermann (1988).

118 Strack (1931).

119 Wruck (1931).

${ }^{120}$ Promotionsakte Paul L. Strack. In: UAHW, Rep. 21, Nr. 678.

121 Vgl. UAGi, O 25.

122 Personal- und Vorlesungsverzeichnis der Universität Halle, Halle 1931, S. 55 (SoSe 1931); Halle 1933, S. 53 (SoSe 1933); Halle 1933, S. 54 (WiSe 1933/34).

${ }^{123} \mathrm{MvB}$ (1923), S. XI.

${ }^{124} \mathrm{Vgl}$. UAHW 4080.

${ }^{125}$ Bericht über die siebzehnte Versammlung Deutscher Historiker zu Halle a. d. S. (1930), S. 65.

${ }^{126}$ Personalnachrichten (1931).
} 
Universität vertrieben wurde, in seinem „Numismatischen Literatur-Blatt“ ein Forum zur Publikation bot, dürfte in erster Linie dem gemeinsamen Interesse für das antike Geld geschuldet gewesen sein. Ergänzende Motive könnten Boschs Kriegsteilnahme 1917 bis 1919 und die Kollegialität als Universitätsdozenten gewesen sein. ${ }^{127}$

Im Frühjahr 1935 wandte sich der betagte Hochschullehrer an den Dekan der Philosophischen Fakultät und erklärte, dass er seine Vorlesungen altersbedingt zum Wintersemester 1935/36 einstellen werde. ${ }^{128}$ Kurz nachdem der „Exzellenz“ noch die besten Wünsche der Kollegen zum 80. Geburtstag übermittelt worden waren, ${ }^{129}$ verstarb er nach schwerer Erkrankung am 11. April 1936 in Halle. ${ }^{130}$ Die Todesanzeige der Familie wies darauf hin, dass nach der Einäscherung eine Trauerfeier am 15. April 1936 in der großen Kapelle des Gertrauden-Friedhofs stattfinden werde. ${ }^{131}$ Rektor Emil Woermann (1899-1980) kondolierte der Witwe, lud alle Gruppen der Universität zur Trauerfeier ein und notierte: „6.) Kranz bestellen (Preis 20 RM). 7.) Am 15. April 1936 Halbmast flaggen (Hauptgebäude)“. ${ }^{132}$ Seine letzte Ruhestätte fand der ehemalige Offizier in Fürstenwalde. ${ }^{133}$ Zwei Wochen nach dem Hinscheiden ihres Gatten wandte sich Ella von Bahrfeldt an Woermann, um der Universität den Nachlass zu verkaufen, der aus Fachbüchern zum mittelalterlichen Niedersachsen und zur Antike, Zeitschriftenbänden, der Abguss-Sammlung von Münzen sowie geprägtem „Notgeld“ bestand. ${ }^{134}$ Ob später nach dem Willen der Witwe verfahren wurde, geht aus der Personalakte nicht hervor. Im Dezember 1936 hielt die Philosophische Fakultät über den verstorbenen „Soldaten echt preussischer Art“ fest: „Ein deutscher General des Weltkrieges, ein bedeutender Forscher und nicht zuletzt ein beispielhafter und geliebter Lehrer der studentischen Jugend - so wird er in unserem Andenken fortleben." ${ }^{135}$

\section{Zusammenfassung}

Als Berufssoldat und hochdekorierter Truppenkommandeur nahm der aus der Uckermark stammende Max von Bahrfeldt eine Sonderrolle innerhalb der deutschen Altertumswissenschaft ein. Er gehörte der militärisch-preußischen Elite an, unterstand der Befehlsgewalt der Wilhelminischen Kaiser und hatte nationalistische Positionen verinnerlicht. Auf der Karriereleiter des Offizierskorps stieg er rasch empor. Privat fand er in der Ehe mit Ella Samwer, aus der vier Kinder hervorgingen, sein Glück. Durch eine privilegierte Sozialisation wies er eine exzellente wissenschaftliche Schulung auf, beherrschte mehrere Sprachen und entwickelte ein spezielles Interesse für die kultur- und wirtschaftshistorische Münzkunde. Damit war die Grundlage für eine über 50 Jahre währende Herausgabe einer Informationszeitschrift, des „Numismatischen Literatur-

\footnotetext{
${ }^{127}$ Z. B. Bosch (1930); Bosch (1931); Bosch (1934); Bosch (1935); Adak / Ehling (2009); Ehling (2012).

${ }^{128}$ Dekan der Philosophischen Fakultät an den Kurator der Universität Halle-Wittenberg am 17.5.1935. In: UAHW 4080.

${ }^{129}$ Personalnachrichten (1936), S. 406.

${ }^{130}$ Max Woermann an die Gremien der Universität Halle-Wittenberg am 13.4.1936. In: UAHW 4080.

${ }^{131}$ Todesanzeige der Familie von Max von Bahrfeldt (Ort und Datum nicht ersichtlich). In: UAHW 4080.

132 Notizen Emil Woermann am 13.4.1936. In: UAHW 4080.

${ }^{133}$ Ella von Bahrfeldt, Dankesschreiben an den Rektor der Universität Halle-Wittenberg am 26.4.1936. In: UAHW 4080.

${ }^{134}$ Ella von Bahrfeldt, Nachlass-Anfrage an den Rektor der Universität Halle-Wittenberg am 26.4.1936. In: UAHW 4080.

${ }^{135}$ Philosophische Fakultät der Universität Halle Wittenberg am 2.12.1936. In: UAHW 4080; vgl. Woermann (1937), S. 14.
} 
Blatts“, gelegt. Auch prädestinierten ihn Beruf und Passion für zahlreiche Auslandsreisen in die Kabinette und Museen Europas, die er seit 1875 regelmäßig durchführte.

Sein erstes wissenschaftliches Standbein bildete das Studium der niedersächsischen Währungen in Mittelalter und Neuzeit. Unter sorgfältiger Auswertung der finanztechnischen Akten betroffener Städte und Regionen richtete sich sein Augenmerk vorrangig auf die sog. „Kipper- und Wipperzeit“" des 17. Jahrhunderts. Das mächtige, vierbändige „Niedersächsische Münzwerk“ kann als typisch für diese Materie angesehen werden. Immer wieder kreisten seine Untersuchungen um das Geldwesen der Stadt Hildesheim, wo er zeitweilig seinen Wohnsitz eingenommen hatte. Nach dem Ersten Weltkrieg zog das „Notgeld“ seine Aufmerksamkeit auf sich, das deutsche Städte und Länder herausgegeben hatten, um ihre Währungsprobleme in den Griff zu bekommen. Als zweites numismatisches Standbein von Bahrfeldts kristallisierte sich die Münzprägung des Imperium Romanum, besonders der Epoche der republikanischen Ära und der Übergangszeit zum Prinzipat, heraus. Als Bezugspunkt und methodologisches Vorbild dienten ihm Theodor Mommsen und seine bahnbrechenden Forschungen zur römischen Münzgeschichte. In zahlreichen Studien beschäftigte er sich intensiv mit Metrologie und Chronologie, frühen Prägestätten, dem Material, dem Gewicht, den Motiven, Stempeln, Münzfüßen, Zirkulationsgebieten und einzelnen Zahlungsmitteln, vom Kupfer-, Bronze- und Silbergeld bis zur Goldwährung des Aureus unter der Diktatur Caesars.

Schon seine erste Reise führte den Münzspezialisten der römischen Republik nach Paris in das „Cabinet des médailles“ und brachte ihn in Kontakt mit dem französischen Experten Henry Cohen. Als gut vernetzter Numismatiker und polyglotter Herausgeber von Zeitschriften rezipierte er die internationale Forschung und war Teil der europäischen Community, die in Harold Mattingly, Edward A. Sydenham, Ernest Babelon, William Henry Waddington, den Brüdern Gnecchi, Friedrich Imhoof-Blumer, Alfred von Sallet, Kurt Regling und Behrendt Pick führende Repräsentanten besaß. In Deutschland, aber auch im Ausland, besaß sein Name eine unangefochtene Autorität. Ressentiments sorgten jedoch dafür, dass er gegenüber französischen Publikationen starke Vorbehalte an den Tag legte. Insbesondere der langjährige Antipode Ernest Babelon musste nicht selten als Zielscheibe von kleinlicher Rechthaberei und Korrekturwut herhalten.

Die diplomatischen Spannungen im Sommer 1914 führten dazu, dass der geadelte und in den Ruhestand versetzte von Bahrfeldt wieder reaktiviert wurde. Der Regimentskommandeur hatte den raschen Vormarsch durch das neutrale Belgien in Richtung Frankreich zu unterstützen. Da die deutschen Soldaten in der Industriestadt Charleroi auf hartnäckigen Widerstand stießen, gab er seinen Truppen den Befehl, diesen durch scharfes Vorgehen zu brechen. Die Instruktionen des Brandenburgers schlossen die Einrichtung von Standgerichten und Erschießung von Zivilisten ein. Wegen dieser Kriegsverbrechen, denen laut Anklage 29 Menschen zum Opfer fielen, verurteilte ihn ein hohes Gericht im belgischen Mons 1925 in Abwesenheit zum Tode. Zuvor hatten in der Weimarer Republik mehrere deutsche Regierungen und der Reichsgerichtshof die schützende Hand über ihn gehalten, seine Auslieferung verhindert und eine Bestrafung unterbunden. Das Gefühl, dass ihm juristisch Unrecht widerfahren und sein international makelloser Ruf geschädigt worden sei, veranlasste den betagten Münzkundler, noch 1935 (!) eine Dokumentation der Ereignisse zu veröffentlichen, in der er seine Sicht der Dinge darlegte und darauf beharrte, rechtmäßig gehandelt zu haben. Die in dieser Schrift zum Ausdruck kommende abfällige Bezeichnung der belgischen Bevölkerung zeigt den sonst so nüchternen und vermeintlich objektiven Gelehrten als elitären Nationalisten und lässt seine geistige Nähe zum frühen Nationalsozialismus erkennen. 
Nach dem Sturz der Monarchie in Deutschland startete von Bahrfeldt unter demokratischen Verhältnissen eine späte Karriere als Hochschullehrer. Er wurde Ende des Jahres 1921 außerordentlicher Professor für Münzkunde an der Universität Halle-Wittenberg. Auch in seiner neuen beruflichen Position legte er eine bewundernswerte Konstanz an den Tag und bot seine „hilfswissenschaftlichen“ Veranstaltungen für die historisch orientierten Studierenden bis Mitte der 1930er Jahre an. Zu seinen Schülern gehörten Paul L. Strack und Waldemar Wruck, die meist dem Doktorvater Wilhelm Weber zugeordnet werden. In vielen patriotischen Positionen dürfte er den bekannten Altertumswissenschaftlern seiner Generation, Eduard Meyer (1855-1930), Ulrich von WilamowitzMoellendorff (1848-1931) und Eduard Schwartz (1858-1940), nahegestanden haben. Wie sie verkörperte er eine personelle sowie gedankliche Kontinuität vom obrigkeitsstaatlichen Kaiserreich und verlor im Ersten Weltkrieg einen Sohn (Schwartz sogar zwei). Dass er in deutlich geringerem Maße als die genannten Koryphäen im Gedächtnis der nachfolgenden Generationen geblieben ist, ${ }^{136}$ dürfte nicht nur seiner recht kurzen universitären Phase geschuldet gewesen sein, sondern auch der Tatsache, dass er eher Züge eines Spezialisten vergangener Tage trug und weniger ein moderner Historiker des Altertums vom Schlage eines Mommsen war. Als Musterbeispiel für preußische Exaktheit, Nüchternheit und Disziplin, vielseitiger Numismatiker mit großem Euvre und chauvinistischer Vorgänger nationalsozialistischer Militanz verdient es von Bahrfeldt, stärker als bisher beachtet zu werden.

\footnotetext{
${ }^{136}$ Nur Crowford (1974) scheint die Publikationen Max von Bahrfeldts intensiver rezipiert zu haben.
} 


\section{Quellen- und Literaturverzeichnis}

\section{A. Archivalien}

\section{Universität Gießen (UAGi)}

UAGi Phil O 24, Ehrenpromotion Max Bahrfeldt 1911.

\section{Universität Halle Wittenberg (UAHW)}

UAHW PA 4080, Max von Bahrfeldt 1921-1936, 2 Teile (der Personalbogen in UAHW, Rep. 6, Nr. 1407 ist identisch mit dem in PA 4080).

\section{B. Max von Bahrfeldt (MvB), ausgewählte Publikationen}

-, (1876a), Numismatisch-sphragistischer Anzeiger. In: Numismatisch-sphragistischer Anzeiger 7, S. 1-2.

-, (1876b), Contremarken Vespasians auf römischen Familiendenaren. In: Zeitschrift für Numismatik 3, S. 354-374.

-, (1879), Die Münzen der Stadt Stade, Wien.

-, (1880), An unsere Abonnenten. In: Numismatisches Literatur-Blatt 1, S. 1-2.

-, (1883), Geschichte des älteren römischen Münzwesens bis circa 200 v. Chr. (554 der Stadt). In: Numismatische Zeitschrift 15, S. 5-215.

-, (1886/87), Contremarken Vespasians auf römischen Familiendenaren. Neue Zusammenstellung. In: Zeitschrift für Numismatik 14, S. 67-74.

-, (1892), Die Münzen und das Münzwesen der Herzogtümer Bremen und Verden unter schwedischer Herrschaft 1648-1719. Zugleich Beiträge zur deutschen Geld- und Münzgeschichte des 17. Jahrhunderts, Hannover.

-, (1893), Beiträge zur Münzgeschichte der Lüneburgischen Lande im ersten Drittel des 17. Jahrhunderts. Herzog Wilhelm von Harburg, Christian zu Celle, Julius Ernst und August d. J. zu Dannenberg-Hitzacker, Wien.

-, (1895), Überprägte Münzen aus der Zeit der römischen Republik. In: Zeitschrift für Numismatik 19, S. 72-90.

-, (1896/97), Nachträge und Berichtigungen zur Münzkunde der römischen Republik, im Anschluss an Babelons Verzeichnis der Consular-Münzen. I. In: Numismatische Zeitschrift 28, S. 1-169; 29, S. 1-150.

-, (1899/90), Le monete romano-campane. In: Rivista Italiana di numismatica e science affini 12, S. 387-446; 13, S. 11-85.

-, (1900a), Nachträge und Berichtigungen zur Münzkunde der römischen Republik, im Anschluss an Babelons Verzeichnis der Consular-Münzen. II. In: Numismatische Zeitschrift 32, S. 1-116.

-, (1900b), Babelon, E., Guide illustré au Cabinet des Médailles et Antiques de la Bibliothèque nationale, Paris 1900. In: Numismatisches Literatur-Blatt 21, S. 1037. 
-, (1902), Babelon, E., Traité des monnaies grecques et romaines. Première partie, Tome I, Paris 1901. In: Numismatisches Literatur-Blatt 23, S. 1091-1092.

-, (1904a), Die römisch-sizilischen Münzen aus der Zeit der Republik. In: Revue Suisse de numismatique 12, S. 331-447.

-, (1904b), Ueber die Chronologie der Muenzen des Marcus Antonius 710-724 u. c. (44-30 v. Chr.). In: Atti del Congresso Internazionale di Scienze Storiche, Roma 1-9 aprile 1903. Vol. VI: Numismatica, Roma (NDr. Nendeln / Liechtenstein 1972), S. 187-200.

-, (1905), Die Münzen der Flottenpräfekten des Marcus Antonius. In: Numismatische Zeitschrift 37, S. 9-56.

-, (1909a), 11. Der Numismatiker. In: Numismatisches Literatur-Blatt 30, S. 1413.

-, (1909b), Die letzten Kupferprägungen unter der römischen Republik. In: Numismatische Zeitschrift 42, S. 67-86.

-, (1914), Die Münzsammlung des Roemer-Museums zu Hildesheim, Hildesheim.

-, (1919), Nachträge und Berichtigungen zur Münzkunde der römischen Republik, im Anschluss an Babelons Verzeichnis der Consular-Münzen. III. In: Numismatische Zeitschrift 51, S. 73-180.

-, (1923), Die Römische Goldmünzenprägung während der Republik und unter Augustus. Eine chronologische und metrologische Studie, Halle (Saale).

-, (1924), Personalnachrichten (Nachruf auf E. Babelon). In: Blätter für Münzfreunde 59 , S. 16.

-, (1925a), 4. Deutscher Münzforschertag zu Halle (Saale) vom 30. September bis 3. Oktober 1925. In: Blätter für Münzfreunde 60, S. 321-323.

-, (1925b), E. J. Haeberlin $\uparrow$ (mit numismatischer Bibliografie). In: Blätter für Münzfreunde 60, S. 369-372.

-, (1926a), Contremarken auf römischen Kupfermünzen der ersten Kaiserzeit. In: Blätter für Münzfreunde 61, S. 395-396.

-, (1926b), Notgeld-Literatur. In: Numismatisches Literatur-Blatt 43, S. 2120-2122.

-, (1926c), Die numismatischen Studien an der Universität Halle-Wittenberg. In: Blätter für Münzfreunde 61, S. 506-509.

-, (1926d), Schaumünzen auf die Gründung der Universität Halle 1694. In: Blätter für Münzfreunde 61, S. 513-520; 529-534.

-, (1927a), Niedersächsisches Münzarchiv, Bd. 1, Halle / Saale 1927. In: Numismatisches Literatur-Blatt 44, S. 2171-2172.

-, (1927b), Notgeld-Literatur. In: Numismatisches Literatur-Blatt 44, S. 2183-2184.

-, (1927-1930), Niedersächsisches Münzarchiv. Verhandlungen auf den Kreis- und Münzprobationstagen des Niedersächsischen Kreises 1551-1625, Bde. 1-4, Halle / Saale.

-, (1928a), Die Notmünzen der Stadt Hamm (Westf.) 1917 bis 1919, Halle / Saale. 
-, (1928b), Anzeige: Die Notmünzen der Stadt Hamm (Westf.) 1917 bis 1919, Halle / Saale 1928. In: Numismatisches Literatur-Blatt 45, S. 2235.

-, (1929), Ernst Justus Haeberlin. Sein Wirken in Wissenschaft und Leben, München.

-, (1930a), Corpus inscriptionum latinarum. In: Numismatisches Literatur-Blatt 47, S. 2475-2476.

-, (1930b), Die Notmünzen der Provinzen Ost- und Westpreußens 1916-1921, Halle / Saale.

-, (1930c), Verzeichnis der Schriften münzwissenschaftlichen Inhalts Dr. Emil Bahrfeldts. In: Blätter für Münzfreunde 65, S. 10-16; 82-86.

-, (1931), Cohen, Henry, Description historique des monnaies frappées sous l'empire romain, communément appelées Médailles impériales. Deuxième édition, 8 Bde., Leipzig 1930. In: Numismatisches Literatur-Blatt 48, S. 2490-2491.

-, (1932a), Das geprägte Notgeld der Gemeinden des Freistaates Baden 1916-1921, Halle / Saale.

-, (1932b), Die Münzen- und Medaillen-Sammlung in der Marienburg. Registerband. Gesamtregister über die Bände I-VII, Königsberg i. Pr.

-, (1933), 50! In: Numismatisches Literatur-Blatt 50, S. 2661.

-, (1933/34), Meine numismatische Reise nach Spanien und Portugal 1928. In: Blätter für Münzkunde 68, S. 742-744; 754-755; 69, S. 18-20.

-, (1935a), Das geprägte amtliche Notgeld der Provinz Schlesien 1917-1921, Breslau.

-, (1935b), Kriegsverbrecher Nr. 10. Zur Erinnerung an das vor 10 Jahren durch das belgische Kriegsgericht zu Mons über mich gefällte Todesurteil, Breslau.

\section{Verwendete Literatur:}

Adak, Mustafa / Ehling, Kay (2009), "Ich muss anmerken, dass ich nicht die Absicht habe, nach Deutschland zurückzukehren." Exil und neue Heimat. Clemens Bosch zwischen Halle und Istanbul (1933-1939). In: Chiron 39, S. 271-296.

Alföldi, Andreas (1930), Rezension Mattingly, Harold / Sydenham, Edward, The Roman imperial coinage. Bd. III. Antoninus Pius to Commodus, London 1930. In: Numismatisches Literatur-Blatt 47, S. 2444-2445.

Alföldi, Andreas (1931), Rezension Kornemann, Ernst, Doppelprinzipat und Reichsteilung im Imperium romanum, Leipzig 1930. In: Numismatisches LiteraturBlatt 48, S. 2476-2478.

Babelon, Ernest (1885/86), Description historique et chronologique des monnaies de la république romaine, vulgairement appelées monnaies consulaires, 2 Bde., Paris, NDr. Bologna 1963.

Bahrfeldt, Emil (1901-1929), Die Münzen- und Medaillensammlung in der Marienburg, 7 Bde., Königsberg.

Baldin, Damien / Saint-Fuscien, Emmanuel (2012), Charleroi. 21-23 août 1914, Paris. 
Berger, Frank (1989), Die Münzen der Römischen Republik im Kestner-Museum Hannover. 100 Jahre Kestner-Museum Hannover 1889-1989, Hannover.

Bericht über die siebzehnte Versammlung Deutscher Historiker zu Halle a. d. S. vom 22. bis 26. April (1930), München / Leipzig.

Bosch, Clemens (1930), Rezension Ulrich, Theodor, Pietas (pius) als politischer Begriff im römischen Staate bis zum Tode des Kaisers Commodus, Breslau 1930. In: Numismatisches Literatur-Blatt 47, S. 2431-2432.

Bosch, Clemens (1931), Rezension Berve, Helmut, Griechische Geschichte. Bd. 1. Von den Anfängen bis Perikles, Freiburg i. Br. 1931. In: Numismatisches Literatur-Blatt 48, S. 2552-2553.

Bosch, Clemens (1934), Rezension The Roman Imperial Coinage, Hrsg. von Harold Mattingly / Edward A. Sydenham, Vol. V, Part II, by Percy H. Webb, London 1933. In: Numismatisches Literatur-Blatt 51, S. 2761.

Bosch, Clemens (1935), Die kleinasiatischen Münzen der römischen Kaiserzeit, Teil II, Bd. 1: Bithynien, 1. Hälfte, Stuttgart.

Bourlier, Pierre-Philippe Baron d'Ailly (1866), Recherches sur la monnaie romaine depuis son origine jusqu'à la morte d'Auguste, Tome II, 1re Partie, Lyon.

Buck, Heinrich / † Max von Bahrfeldt (1937), Die Münzen der Stadt Hildesheim, Hildesheim / Leipzig.

Catalogus Professorum Halensis (2021). In: http://www.catalogus-professorum.halensis.de (online-ressource, Zugriffe am 11. Januar 2021).

Christ, Karl (1990), Andreas Alföldi (1895-1981). In: Ders., Neue Profile der Alten Geschichte, Darmstadt, S. 8-62.

Christ, Karl (2006), Klios Wandlungen. Die deutsche Althistorie vom Neuhumanismus bis zur Gegenwart, München.

Cohen, Henry (1859-1868), Description historique des monnaies frappées sous l'empire romain communément appelées medailles impériales, 8 Bde., Paris, NDr. Graz 1955-1957.

Crawford, Michel H. (1974), Roman Republican Coinage, 2 Bde., Cambridge, NDr. 2019.

Dressel, Heinrich (1904), Nekrolog Theodor Mommsen. In: Zeitschrift für Numismatik 24, S. 367-372 (nebst Verzeichnis der numismatischen Schriften, S. 372-376).

Eberle, Hendrik (2002), Die Martin-Luther-Universität in der Zeit des Nationalsozialismus 1933-1945, Halle / Saale.

Ehling, Kay (2012), Bosch, Clemens. In: Geschichte der Altertumswissenschaften, Sp. 138-139.

Erdmann, Karl Dietrich (1987), Die Ökumene der Historiker. Geschichte der Internationalen Historikerkongresse und des Comité International des Sciences Historiques, Göttingen.

Gaettens, Richard (1936), Max von Bahrfeldt †. In: Blätter für Münzfreunde 71, S. 409-415. 
Gaettens, Richard (1937), An die Leser. In: Numismatisches Literatur-Blatt 53, S. 2875-2876.

Geldgeschichte vs. Numismatik (2004). Theodor Mommsen und die antike Münze. Kolloquium aus Anlaß des 100. Todestages von Theodor Mommsen (1817-1903). Hrsg. von Hans-Markus von Kaenel u. a., Berlin.

Gelehrte Gesellschaften und Vereine (1924). In: Blätter für Münzfreunde 59, S. 15$16 ; 32 ; 48 ; 128$.

Gelehrte Gesellschaften und Vereine (1936). In: Blätter für Münzfreunde 71, S. 475476.

Geschichte der Altertumswissenschaften (2012). Biographisches Lexikon. Hrsg. von Peter Kuhlmann / Helmuth Schneider (Der Neue Pauly, Suppl. Bd. 6), Stuttgart / Weimar.

Gothaisches Genealogisches Taschenbuch der Adeligen Häuser (1941), Teil B, 33, Gotha.

Hirsch, Johann Christoph (1756-1768), Des Teutschen Reichs Münzarchiv, 9 Bde., Nürnberg, NDr. München 1977/78.

Hollstein, Wilhelm (2004), Mommsen und die Chronologie der römisch-republikanischen Münzen. In: Geldgeschichte vs. Numismatik, S. 173-191.

Horne, John / Kramer, Alan (2004), Deutsche Kriegsgreuel 1914. Die umstrittene Wahrheit, Hamburg.

100 Jahre Archäologisches Museum in Halle 1891-1991 (1991). Zur Geschichte des Robertinums, seiner Sammlungen und Wissenschaftsdisziplinen. Hrsg. von Joachim Ebert, Halle / Saale.

Jesse, Wilhelm (1953), Bahrfeldt, Max von. In: Neue Deutsche Biographie 1, S. 543.

Körte, Alfred (1919), Max Leberecht Strack. Geb. den 9. September 1867, gest. den 10. November 1914. In: Biographisches Jahrbuch für die Altertumswissenschaft 39, S. 1-16.

Kolb, Frank (2012), Alföldi, Andreas. In: Geschichte der Altertumswissenschaften, Sp. 15-18.

Krafft, Karl (1907), Handbuch für die Vorbereitung zur Kriegsakademie. Zugleich ein Ratgeber für die wissenschaftliche Beschäftigung jüngerer Offiziere, Berlin, 2. Aufl.

Kürschners Deutscher Gelehrten-Kalender (1931), 4. Ausgabe, Berlin / Leipzig.

Lindenlauf, Astrid (2016), Georg Heinrich Karo (1872-1963). In: Lebensbilder. Klassische Archäologen und der Nationalsozialismus. Hrsg. von Gunnar Brands / Martin Maischberger, Bd. 2, Rahden, S. 55-78.

Lipkes, Jeff (2007), Rehearsals. The German Army in Belgium, August 1914, Leuven.

Meißner, Burkhard (2002), Forschung, Lehre und Organisation des Lehrstuhls für Alte Geschichte der Universität Halle im 20. Jahrhundert. In: Beiträge zur Geschichte der Martin-Luther-Universität Halle-Wittenberg 1502-2002. Hrsg. von Hermann-J. Rupieper, Halle / Saale, S. 223-242. 
Mommsen, Theodor (1860), Geschichte des römischen Münzwesens, Berlin, NDr. Graz 1956.

Personalnachrichten (1926). In: Blätter für Münzfreunde 61, S. 512.

Personalnachrichten (1931). In: Blätter für Münzfreunde 66, S. 235.

Personalnachrichten (1936). In: Blätter für Münzfreunde 71, S. 405-406.

Personal- und Vorlesungsverzeichnis der Universität Halle-Wittenberg, Halle (Saale) $1921 \mathrm{ff}$.

Pink, Karl (1936), Max von Bahrfeldt †. In: Numismatische Zeitschrift 69, S. 95.

Pressenotiz zu Max von Bahrfeldt (1922). In: Saale-Zeitung vom 3. Januar 1922.

Prokoph, Werner (1985), Der Lehrkörper der Universität Halle-Wittenberg zwischen 1917 und 1945, Halle / Saale.

Regling, Kurt (1922), Heinrich Willers †. In: Zeitschrift für Numismatik 33, S. 139142.

Regling, Kurt (1924a), Rezension von Bahrfeldt, Max , Die römischen Goldmünzenprägung während der Republik und unter Augustus, Halle (Saale) 1923. In: Zeitschrift für Numismatik 34, S. 374-380.

Regling, Kurt (1924b), J. N. Svoronos †. In: Zeitschrift für Numismatik 34, S. 394399.

Regling, Kurt (1924c), E. Babelon $\uparrow$. In: Zeitschrift für Numismatik 34, S. 399-404.

Reichsarchiv (1925). Der Weltkrieg 1914 bis 1918. 14 Bde., Bd. 1: Die Grenzschlachten im Westen, Berlin.

Schubert, Helmut (2012a), Babelon, Ernest. In: Geschichte der Altertumswissenschaften, Sp. 41-42.

Schubert, Helmut (2012b), Cohen, Henry. In: Geschichte der Altertumswissenschaften, Sp. 239-240.

Schulz-Falkenthal, Heinz (1961), Zur Entwicklung des Faches Alte Geschichte an der Universität Halle. In: Wissenschaftliche Zeitschrift der Universität Halle, Gesellschaftswissenschaftliche Reihe, 10, S. 915-926.

Schwengler, Walter (1982), Völkerrecht, Versailler Vertrag und Auslieferungsfrage. Die Strafverfolgung wegen Kriegsverbrechen als Problem des Friedensschlusses 1919/20, Stuttgart.

Steindorff, Ernst (1890), Samwer, Karl. In: Allgemeine Deutsche Biographie (ADB) 30, S. 326-327.

Strack, Paul L. (1931), Untersuchungen zur römischen Reichsprägung des zweiten Jahrhunderts. Teil 1: Die Reichsprägung zur Zeit des Traian, Stuttgart.

Theiler, Willy (1934), Oscar Leuze †. In: Gnomon 10, S. 508-510.

Ungern-Sternberg, Jürgen von (2017), Deutsche Altertumswissenschaftler im ersten Weltkrieg. In: Ders., Les chers ennemis. Deutsche und französische Altertumswissenschaftler in Rivalität und Zusammenarbeit, Stuttgart, S. 247-265. 
Vierter deutscher Münzforschertag zu Halle a. S. (1925). Festschrift den Teilnehmern gewidmet von der Numismatischen Gesellschaft zu Halle, Halle / Saale.

Wannack, Katja (2007), Hermann Dessau. Der fast vergessene Schüler Mommsens und die Großunternehmen der Berliner Akademie der Wissenschaften, Hamburg.

Willers, Heinrich (1909), Geschichte der römischen Kupferprägung vom Bundesgenossenkrieg bis auf Kaiser Claudius, Leipzig / Berlin.

Woermann, Max (1937), Bericht des Rektors. In: Chronik der Martin-Luther-Universität Halle-Wittenberg in Halle (Saale) für den Zeitraum 12. Juli 1933 bis zum 31. März 1936. Hrsg. von Rektor und Senat, Halle / Saale, S. 2-19.

Wruck, Waldemar (1931), Die syrische Provinzialprägung von Augustus bis Traian, Stuttgart.

Zedlitz und Neukirch, Conrad-Dieter Freiherr von (1989), Wahlstatt, Crailsheim.

Zimmermann, Hans-Dieter (1980), Johann Heinrich Schulze und die Münzsammlung des Robertinum. In: Wissenschaftliche Zeitschrift der Martin-Luther-Universität Halle-Wittenberg, Gesellschaftswissenschaftliche Reihe, 29, H. 4, S. 53-59.

Zimmermann, Hans-Dieter (1988), Sammlung antiker Münzen, Halle / Saale.

Zimmermann, Hans-Dieter (1991), Eduard Meyer als hallescher Professor. In: Wissenschaftliche Zeitschrift der Humboldt-Universität zu Berlin, Gesellschaftswissenschaftliche Reihe, 40, H. 9, S. 9-15.

\section{Kontakt zum Autor:}

Dr. Matthias Willing

Glammbergweg 9

D-35039 Marburg

E-Mail: Matthias.Willing@t-online.de

\section{(cc) EY}

Dieser Beitrag ist lizenziert unter einer Creative Commons Namensnennung - 4.0 International Lizenz. 